\author{
Anna Adamska, Zdzisław Pakowski \\ Faculty of Process and Environmental Engineering, Lodz University of Technology \\ 90-924 Łódź, Wólczańska 213, anna.adamska@edu.p.lodz.pl, zdzislaw.pakowski@p.lodz.pl
}

\title{
PRESSURE MEASUREMENT AS A TOOL TO IDENTIFY MOISTURE TRANSPORT MECHANISMS IN CONVECTIVE DRYING OF NON-SHRINKING MATERIAL
}

\begin{abstract}
The drying process is one of the most important stages in the production of building materials. The choice of the drying method affects the chemical and physical properties of the final product. The aim of this research is to measure and analyze the dynamic changes of internal pressure in non-shrinking, porous material during convective drying. In this work the problem will be discussed with special attention to the behavior of rewetted plaster. A commercial gypsum of company PIOTROWICE II (Alpol brand), typically used in construction and decorative plastering was applied. Gypsum was mixed with water in recommended proportion of 0.6 water/gypsum and drying experiments were performed at $50^{\circ} \mathrm{C}$. The changes in sample overall mass as well as pressure and material temperature on the midpoint of sample axis were monitored. On the basis of the obtained experimental data of axial pressure, it is possible to perform a more detailed analysis of mass and heat transfer mechanisms than based on the drying kinetics alone. The pressure trends in the sample allow one to determine the moment of transition from the first to the second drying period, without the need to determine the kinetics of drying. The element of novelty consists of using a direct internal pressure measurement to provide information on the variation of the actual drying rate and mass transfer mechanisms.
\end{abstract}

\section{Key words}

Gypsum, convective drying, internal pressure, mass transfer.

\section{Introduction}

The convection drying process belongs to one of the oldest and most frequently used unit operations in various branches of industry. The drying rate is one of the most important parameter for this process. Setting the process parameters in such a way as to obtain the highest drying rate, on one hand accelerates drying and is justified from the economic point of view, on the other hand, is a factor often deteriorating the quality of the final product. Therefore, in industrial practice it is very important to find an optimum drying rate regarding both energy consumption and the quality of the product obtained. One of the ways to achieve this goal may be the use of new, combined method for controlling the conditions of the drying process in response to the behavior of the dried material.

Analysis of microstructural changes and interaction between water and solid, especially during mass and heat exchange processes, is a key issue, especially for the design of final strength properties of construction products. The use of uncontrolled conditions may lead to the appearance of shrinkage, deformation and cracks, that was described and subjected to modeling in many works e.g. [1-2].

One of the advantages of plaster is its high porosity. This property can facilitate transport of many compounds (moisture, low molecule weight vapors, $\mathrm{CO}_{2}$ etc.) found in indoor or outdoor environments [3]. However, convective drying of freshly cured gypsum is an important stage in their production process. Optimization of this drying process is required to enhance processing efficiency, in terms of energy consumption and production time, without reduction in the product quality. Most presented works on calculations and simulations of heat and mass transport in gypsum boards focused on its application regarding fire resistance and only accounting for water vapor transport. There is a need to find a key parameter to understand the transport of heat and mass phenomena in porous media, which has an effect on structural defects and final mechanical properties [4].

The literature on the subject presents numerous models that allow predicting the moisture content in time and space in building materials. However, it is necessary to perform experiments in which thermal properties will be determined e.g.: thermal conductivity and transport factors for mass transfer such as diffusivity $[5,6]$ or permeability $[7,8]$. 
Previously published papers indicate that minimizing negative effects during convection drying can be achieved by performing the process in non-stationary conditions, i.e. slowing down the process when there is a danger of material destruction and accelerating when there is no such danger. This technique, referred in the literature as "intermittent drying", in most cases consists of a controlled supply of thermal energy that changes at regular or irregular intervals. Most often, the control of introduced changes takes place by means of controllers, e.g. MPC (Model Predictive Control), based on the examined drying kinetics and current readings of the solid temperature or humidity of the drying agent. The relationship between the residence time of the dried material and the humidity of the material and other measured parameters is determined in most cases, by previously developed drying models, sometimes based on neural networks.

The analysis of the pressure evolution within the dried material has already been undertaken in several works. So far, most of the work on convection drying has only considered the existence of capillary pressure. These are mainly considerations based on theoretical dependencies, because the measurement of this pressure is complicated. One of the first reports from experimental research comes from 1996 where the authors suggested a complex procedure for investigating shrinkage stresses in the process of drying colloidal capillaryporous bodies like peat and presented distribution of capillary and internal pressure as a function of moisture content [9]. Attempts to measure and analyze this pressure were made in the work of E. Holt, where the evolution of internal capillary pressure for autogeneous shrinkage of concrete was investigated [10]. However, the pressure generated during mass transport, especially in the case of multiphase flow, is also influenced by the properties of the material itself, hence the difficulty in finding a universal method of measuring this parameter, which gives a lot of meaningful information about the drying process and the ability to control the shrinkage and cracks on the surface of the dried material [11].

This work focuses on the analysis of mass transport phenomena in the drying process, based on the pressure trend in the porous material that does not show any drying shrinkage. The obtained results can be used to control the drying agent parameters directly in response to the changing stresses generated in the structure of the dried material. Thanks to the use of telemetric pressure measurements, it could be used without any problem on an industrial scale.

\section{Materials and methods}

In experimental part a commercial gypsum of company PIOTROWICE II (Alpol brand), typically used in construction and decorative plastering was applied. The skeletal density of prepared samples was $2570 \mathrm{~kg} / \mathrm{m}^{3}$ and the porosity 0.65 .

The preparation of samples for drying experiments included three basic steps described below:

- in the first stage, after mixing gypsum with distilled water in the amount recommended by the producer ( $2.4 \mathrm{dm}^{3}$ per $4 \mathrm{~kg}$ of gypsum), cylinders with a diameter of $28 \mathrm{~mm}$ and a height of $54 \mathrm{~mm}$ were cast in which thermocouples and a syringe needle with attached pressure transducer were used to monitor the temperature and internal pressure on the periphery and on the axis. The axial thermocouple of $0.5 \mathrm{~mm}$ external diameter was passed through the syringe needle of internal diameter of $0.9 \mathrm{~mm}$ (cf. Fig.1) and inserted axially so that the end of the needle was $27 \mathrm{~mm}$ above the cylinder base. This allowed for simultaneous measurement of pressure and temperature in the same point. The prepared samples were left to dry for 24 hours at room temperature,

- in the next step the samples were soaked in distilled water for min. $24 \mathrm{~h}$ to get the material fully saturated,

- the last stage included insulating both bases of the cylinder with hydrocyanide glue so as to ensure one-dimensional mass and heat transport. Each sample before being placed in the drying tunnel was measured and weighed. The appearance of the sample before placing in the tunnel is shown in Fig.1. 


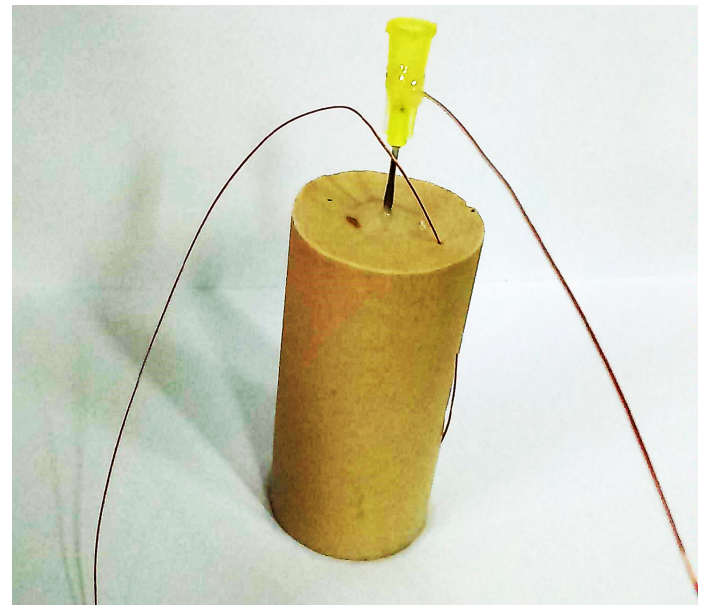

Fig. 1. Cylindrical sample of gypsum with thermocouples and syringe needle for pressure measuring Source: Authors'

To determine the kinetics and temperature curves for the material, a drying tunnel was used as shown in Fig. 2. It is divided into two sections that allow air to circulate. The fixed flow of the drying medium is provided by an axial fan. In the tunnel there is a number of control and measurement devices enabling observation and recording of key process parameters. These devices include an electronic balance by means of which the loss of mass was measured, PT100 sensors to control the temperature in different points in the tunnel as well as air humidity sensor inside the tunnel and atmospheric pressure sensor outside. All readouts were recorded at preset time intervals.

The gypsum cylinders before insertion into the tunnel, were placed on a weighing dish with additional sensors allowing for temperature read out on the sample wall and axis as well as pressure read out in the sample axis at one minute intervals. The relative accuracy of pressure read out was $\pm 0.2 \%$ and the absolute accuracy of temperature read out $\pm 0.5^{\circ} \mathrm{C}$. Absolute accuracy of the weight measurement was $0.001 \mathrm{~g}$.

The dynamic changes of pressure inside the sample were recorded using a MadgeTech pressure sensor that was modified for the experiment and connected directly to the syringe needle inserted in the sample. Both thermocouples and the needle were placed in the samples during plaster casting, so there was no need to drill the sample after its preparation that would deteriorate the contact between the needle and the material. For measuring the current atmospheric pressure a second, identical pressure sensor was used, which was mounted in the laboratory.

The measurements were made at a temperature of $50^{\circ} \mathrm{C}$ at a drying agent speed of $1 \mathrm{~m} / \mathrm{s}$. The recording of parameters was carried out until the equilibrium moisture content was reached (about $7 \mathrm{~h}$ ). To determine the mean moisture content change of the material after drying and dry mass, the samples were placed in an oven and dried to constant weight at $105^{\circ} \mathrm{C}$. The measurements were performed in duplicate for each sample in most cases. The following definitions were used to calculate variables in Fig. 3 and 4.

$$
\begin{gathered}
X=\frac{m_{w . b .}-m_{d . b .}}{m_{d . b .}} \\
w_{D}=\frac{m_{d . b .}}{A} \frac{\Delta X}{\Delta t}
\end{gathered}
$$

where:

$$
\begin{aligned}
& \mathrm{X} \text { - moisture content }\left[\mathrm{kg}_{\mathrm{H} 2 \mathrm{O}} / \mathrm{kg}_{\mathrm{d} \cdot \mathrm{b}}\right] ; \\
& \mathrm{m}_{\text {w.b. }}-\text { mass of wet sample }[\mathrm{kg}] ; \\
& \mathrm{m}_{\text {d.b. }}-\text { mass of dry sample }[\mathrm{kg}] ; \\
& \mathrm{W}_{\text {D. }}-\text { drying rate }\left[\mathrm{kg}_{\mathrm{H} 2 \mathrm{O}} / \mathrm{m}^{2} \mathrm{~s}\right] ; \\
& \text { A. - surface of evaporation }\left[\mathrm{kg}_{\mathrm{H} 2 \mathrm{O}} / \mathrm{m}^{2} \mathrm{~s}\right] ; \\
& \mathrm{t} \text { - time }[\mathrm{s}] .
\end{aligned}
$$


a)

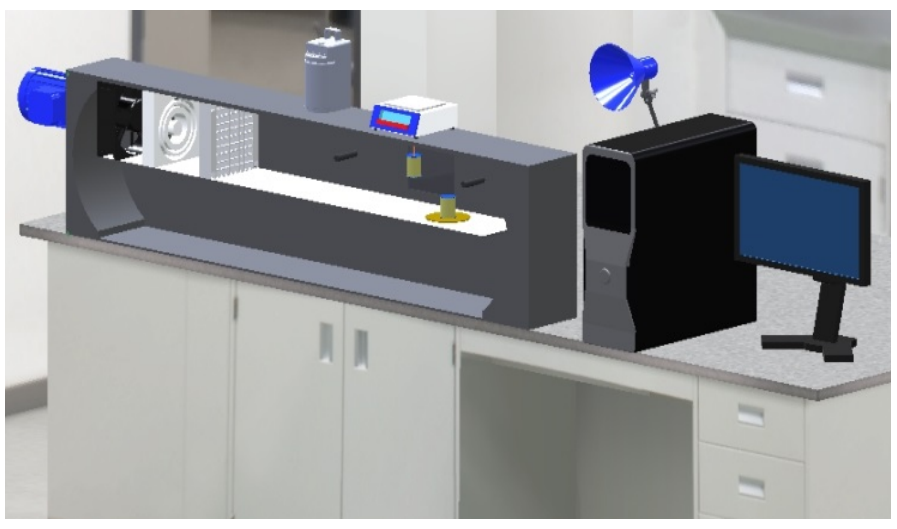

b)

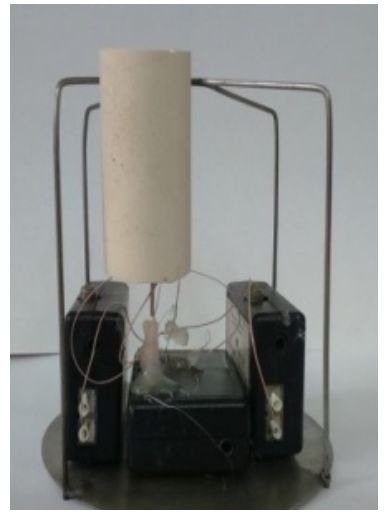

Fig. 2. View of the drying tunnel (a) and sample on weighing dish with temperature and pressure sensor (b) Source: Authors'

To analyze the phenomena occurring during removal of moisture from the material, the difference between the atmospheric pressure and the one measured on the sample axis was used, according to the formula (3):

where:

$$
p_{n}=p_{\text {in }}-p_{\text {atm }}
$$

$\mathrm{p}_{\mathrm{n}}$ - nominal pressure $[\mathrm{Pa}]$;

$\mathrm{p}_{\mathrm{atm}}$ - atmospheric pressure [Pa];

$\mathrm{p}_{\text {in }}$ - internal pressure (absolute) $[\mathrm{Pa}]$

\section{Results}

Fig. 3 presents a set of curves of internal pressure evolution, drying kinetics and temperature for selected measurement series (one of ten performed). It can be clearly seen in graph in Fig. 3 that in the first 20 minutes of drying, the pressure decreases, which is related to the slow process of material heating and removal of moisture mainly due to evaporation of water from the surface of the material. The maximum evaporation rate observed at the beginning of the process generates a large pressure gradient and development of underpressure in the dried material.

After 20 minutes, the pressure on the sample axis gradually increases above the atmospheric pressure, the water evaporates from the core of the rigid skeleton of plaster. After about 1 hour, the pressure reaches a maximum value of approx. $950 \mathrm{~Pa}$. This pressure is maintained for about 1.5 hours and then increases again to about $1150 \mathrm{~Pa}$. The link between pressure change trend in the dried material and the temperature curve is clearly visible here. After analyzing the temperature curve, it can be observed that the pressure begins to increase again after 2 hours from the start of drying, i.e. at the transition from the first to the second drying period, when the material reaches a temperature higher than the wet-bulb temperature. Then the pressure increases with the temperature and after reaching the gas temperature the pressure drops. It should be noted here that the samples were put into the drying tunnel immediately after the removal from the distilled water (after blotting the excess of liquid), therefore the initial temperature of the material is about $10^{\circ} \mathrm{C}$.

In the $4^{\text {th }}$ hour of the process the pressure stabilizes at the level higher that atmospheric pressure. It can be explained by the fact that while soaking the gypsum samples, a migration of microcrystals is observed and during drying these crystals are transported with the stream of moisture from core to the surface and clog pores of the material. This phenomenon is also connected to porosity changes during drying [12].

In the first period of drying in the gypsum pores there is only liquid physically bound with the skeleton. In the second drying period moisture transport resistance is much larger, the water is removed in the form of vapor, therefore the efficiency of the process decreases. In the first drying period the Darcy stream is dominant and in the second period the diffusion transport prevails. The nature of the pressure changes in the sample also indicates the presence of evaporation front, observed as a steep reduction of pressure after 3.5 hours. 


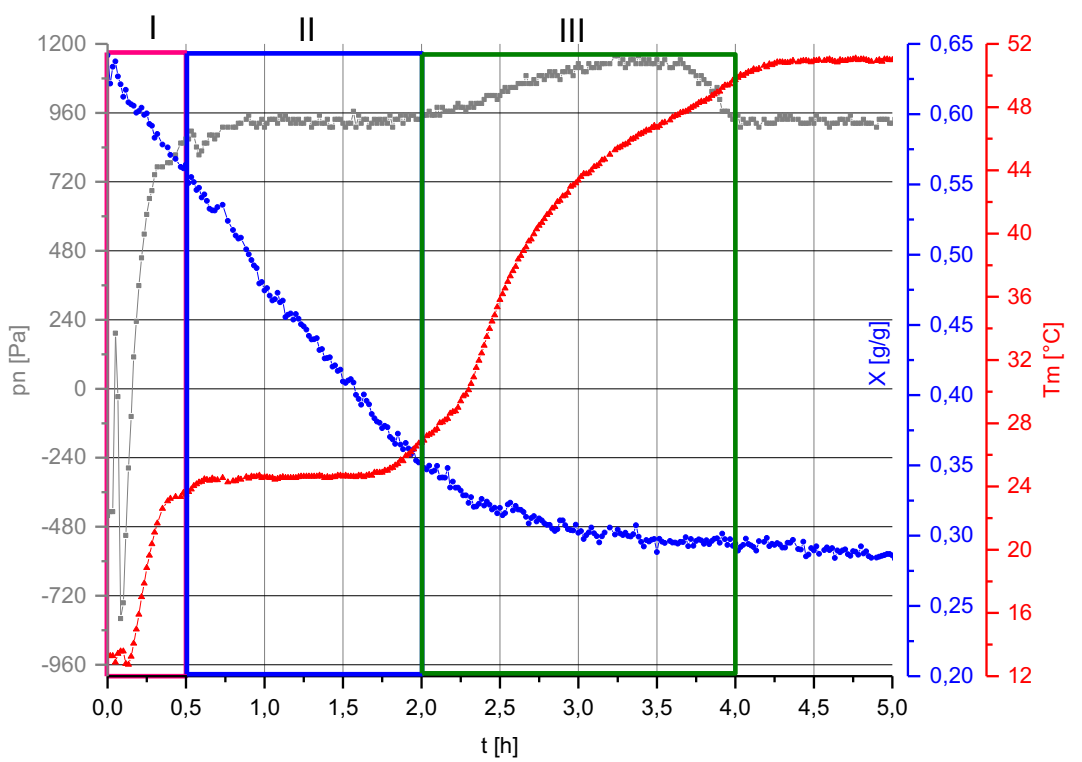

Fig. 3. The pressure $(\square)$, temperature $(\Delta)$ and mean moisture content $(\bullet)$ data points for experimental series \#7 Source: Authors'

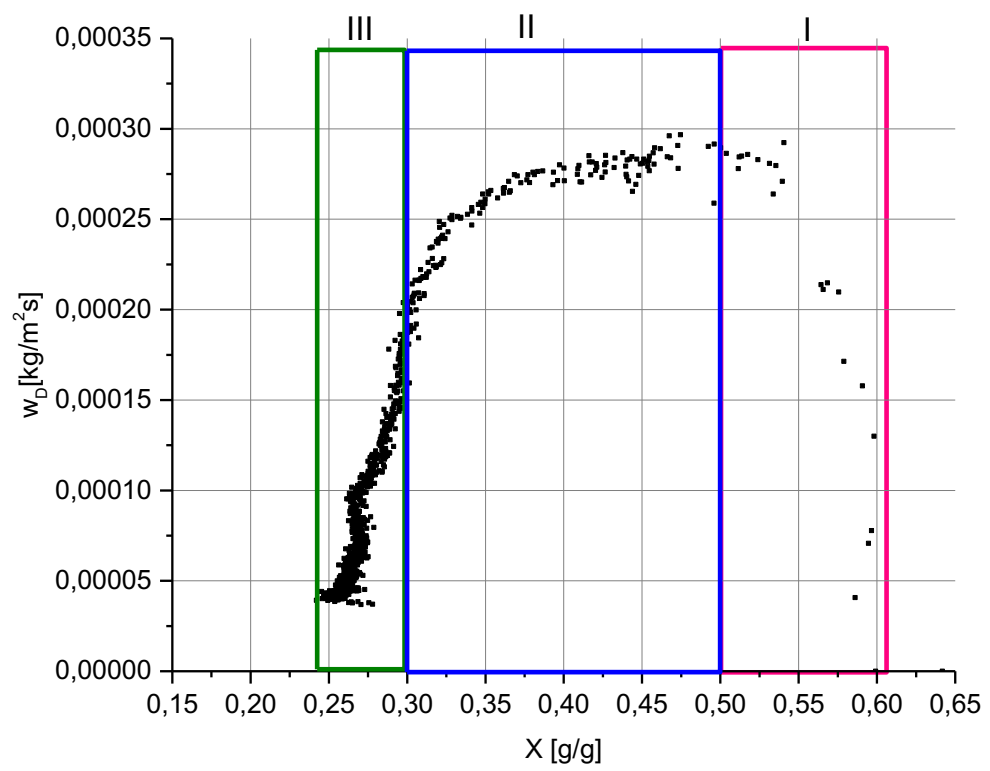

Fig. 4. The drying rate data points for experimental series \#7 Source: Authors'

In Fig. 3 and 4 the areas of characteristic change in the pressure course are marked, for each measured parameter. The calculated drying rate for series \#7 is presented in Fig. 4 . When the evaporation stream in the second characteristic area is maximal the internal pressure stays at the same level. However, when the drying rate in the last stage of process decreases, the internal pressure rises again. This observation contradicts the claim that the water transport is more important for stress generation than that the heat transport during drying [13].

On the basis of the drying kinetics alone only the moment of transition from the first to the second drying period can be determined, similarly as for the temperature curve. The pressure course inside the material additionally shows quite intense phenomena related to tensile and compressive stresses, which appear mainly 
during the heating of the material in the first drying period and additional phenomena present in the second drying period associated with the relaxation of the material.

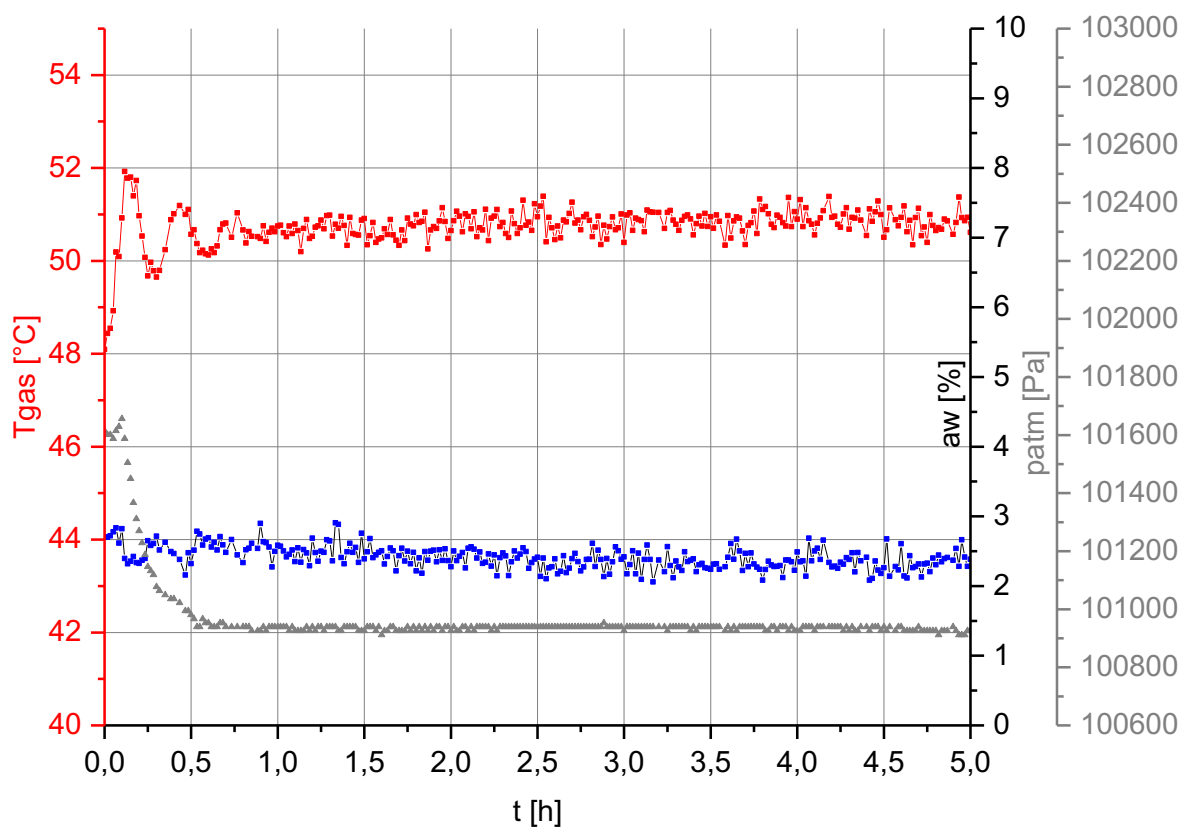

Fig. 5. Parameters of drying air: pressure $(\square)$,temperature $(\boldsymbol{\Delta})$ and humidity $(\bullet)$ for experimental series \#7 Source: Authors'

Fig. 5 presents the dynamic changes in temperature, air humidity and atmospheric pressure for drying agent. The significant fluctuations can be observed for the reference (atmospheric) pressure, what should be included in the calculation of internal pressure and also modeling calculations. In most of the works connected with drying modeling this value is constant. So far the evolution of internal pressure was only predicted by some advanced models [14-16]. They concentrated on the analysis of drying-related stresses in materials of relatively small shrinkage: kaolin, unglazed ceramics and wood, which is directly related to process control in order to avoid product defects. Moreover the theoretically predicted pressure values are usually much higher than the ones observed in this work. No experimental work, including $[9,10]$, so far has presented the evolution of internal pressure in such detail as the present work.

Based on the presented results, it can be concluded that the internal pressure is more sensitive to changes occurring in the material than the temperature or mass change and can be used to control the drying process.

\section{Conclusions}

The analysis of pressure changes inside the drying non-shrinking material, enables more precise observation of phenomena of moisture transport and changes in the nature of stresses generated in the dried material (initially compression and then stretching of the material). In addition, it clearly shows where the transition from the first to the second drying period takes place.

The obtained results will enable us to build a mathematical model to describe the convection drying process taking into account the pressure gradient. Due to that, it will be possible to follow the drying stresses generated in the material on a regular basis and control the process parameters so as to obtain the desired product without defects.

Thanks to the use of telemetric pressure measurements, the method can be easily applied in an industrial scale to control the drying process. It is an ideal solution that can also be used for materials that exhibit shrinkage such as ceramic products and also to predict when the drying shrinkage ends. However, the analysis of pressure changes in shrinking materials is more intricate and is outside the scope of this work. 


\section{References}

[1] C.M. Tam, V.W.Y. Tam, K.M. Ng, Assessing drying shrinkage and water permeability of reactive powder concrete produced in Hong Kong, Construction and Building Materials, 26 (2012) , 79-89.

[2] S.D. Beyea, B.J. Balcom, T.W. Bremner, P.J. Prado, A.R. Cross, R.L. Armstrong, P.E. Grattan-Bellew, The influence of shrinkage-cracking on the drying behaviour of White Portland cement using single-point imagining (SPI), Solid State Nuclear Magnetic Resonance, 13, (1998) , 93-100.

[3] M. Kalender, Determination of effective diffusivities and convective coefficients of $\mathrm{CO}_{2}$ in gypsum plasters by dynamic single pellet experiments, Building and Environment, 105, (2016) , 164-171.

[4] T. Defraeye, G. Houvenaghel, J. Carmeliet, D. Derome, Numerical analysis of convective drying of gypsum boards, International Journal of Heat and Mass Transfer, 55, (2012) , 2590-2600.

[5] O.C.G. Adan, Determination of moisture diffusivities in gypsum renders, HERON-ENGLISH EDITION, 40, (1995), 201-216.

[6] L. Bennamoun, L. Kahlerras, F. Michel, L. Courard, T. Salmon, L. Fraikin, Determination of moisture diffusivity during drying of mortar cement: experimental and modeling study, International Journal of Energy Engineering, 3, (2013) , 1-6.

[7] H., Milsch, M., Priegnitz, G. Blöcher, Permeability of gypsum samples dehydrated in air, Geophysical Research Letters, 38, (2011).

[8] L. C. Yee, Water desorption characteristic of red gypsum, (2015), 1-24.

[9] N.I. Gamayunov, S.N. Gamayunov, Change in the structure of colloidal capillary-porous bodies in the process of heat and mass transfer, Journal of Engineering Physics and Thermophysics, 69, 721-725, (1996)

[10] E.E. Holt, Early age autogenous shrinkage of concrete, Technical Research Centre of Finland, VTT Publications 446, (2001).

[11] Handbook of Porous Media , Third Edition, Edited by Kambiz Vafai, CRC Press, Chapter 2, (2015), 47-62.

[12] S. Klin, Analysis of the variation of strength and deformability of gypsum in various states of stress and humidity, Institute Of Environmental Engineering, Zeszyty Rolnicze Akademii Naukowej we Wrocławiu, 510, (2005), 1-30.

[13] J.L. Amoros, E. Sanchez, V. Cantavella, J.C. Jarque, Evolution of the mechanical strength of industrially dried ceramic tiles during storage, Journal of the European Ceramic Society, 23, (2003), 1839-1845.

[14] A. Rybicki, Sterowanie procesami suszenia materiałów wrażliwych na uszkodzenia skurczowe. Wydawnictwo Politechniki Poznańskiej, 482, (2012), 116.

[15] G. Musielak, Modelowanie i symulacja numeryczna zjawisk transportu oraz naprężeń suszarniczych w materiałach kapilarno-porowatych, Wydawnictwo Politechniki Poznańskiej, 386, (2004), 147.

[16] S.J. Kowalski, A. Rybicki, K. Rajewska, Intensification of drying processes due to optimal operations, Chemical Engineering and Processing, 86, (2014), 22-29. 